EPRA International Journal of Multidisciplinary Research (IJMR) Peer Reviewed Journal

\title{
THE NATIONAL CAPITAL UNDER THE EFFECT OF SEVERE AIR POLLUTION - A CONCERN FOR COMMUNITY LIVING AND EXISTENCE
}

\author{
Dr Yashoda Tammineni \\ HOD, HSE Department \\ National Institute of Fire Engineering and Safety Management \\ Visakhaptnam \\ Andhra Pradesh
}

DOI: https://doi.org/10.36713/epra3779

\begin{abstract}
It's of great concern to observe that the capital of our country, Delhi is under the severe grip of air pollution since a couple of days sending most alarming indications even for a national emergency. The Air quality index (AQI) entered the "severe plus" or "emergency" category and the Pollution levels in Delhi peaked to a three-year high in the month of November this year. Alarmingly, the level of particulate matter (PM) in the air reached intolerable level and the real time AQI was as high as 999 at monitoring stations at many places in Delhi. The smog (smoke and fog) has reached such an intolerable state that the people are suffering from severe pulmonary disorders and the visual clearance has enormously reduced leading to road accidents and even effected the air trafficking. Until and unless the AQI comes down drastically general living conditions in Delhi seems to be next to impossible.
\end{abstract}

KEYWORDS: Air quality index (AQI), PM 2.5 Pollution, PM 10 Pollution, Severe Smog, Pulmonary disorders

\section{INTRODUCTION}

The onslaught of smog effect on Delhi is there since 17 years. As winter advances the particulates including dust, smoke from industrial effluents, vehicular emissions, and other domestic sources like burning of waste are causing heavy damage to the environment.

The entire city is enveloped by pollution layer all around with contribution from multiple sources within Delhi, nearby region and even from long distances.[1] Air pollution in Delhi is the result of anthropogenic and natural sources like road dust. Anthropogenic pollutants mainly like crop burning, waste burning and the ever increasing number of vehicles in Delhi is causing a great concern regarding concentration of Nitrous oxide levels. Air Quality Index (AQI) indicates the environment condition. 1-50 consider to be good, 51-100 satisfactory, 101-200 moderate, $201-300$ poor, $301-400$ very poor, 401-500 severe, 500 and above emergency while the prescribed standard for PM10 and PM2.5 is 100 and $60 \mathrm{ug} / \mathrm{m}^{3}$ respectively. 


\begin{tabular}{|c|c|}
\hline AQI Category & Index Values \\
\hline Good & $0-50$ \\
\hline Moderate & $51-100$ \\
\hline $\begin{array}{c}\text { Unhealthy for } \\
\text { Sensitive Groups }\end{array}$ & $101-150$ \\
\hline Unneaithy & $151-200$ \\
\hline Very Unhealthy & $201-300$ \\
\hline Hazardous & $301-400$ \\
\hline
\end{tabular}

Image Source : https://study.com/cimages/multimages/16/airqualityusscale.jpg

The satellite images of NASA's fire mapper revealed that the cases of paddy burning in Punjab, Haryana and Uttar Pradesh increased after Diwali (October 30). It led to severe smog in the national capital.[2]

Levels of PM10, PM2.5 and $\mathrm{NO}_{2}$ are statistically higher (at most locations) in winter months than in summer months by about 25-30 percent. In general air pollution levels in ambient air are uniform across the city suggesting entire city is stressed under high pollution. ${ }^{[3]}$ During Diwali days, PM levels nearly double from the average level and organic content of
PM increases more than twice. It is noteworthy that levels of potassium and barium, the main components of fire crackers can increase by about ten times.

2. BURDEN OF PM 2.5 AND PM 10 EMISSION IN DELHI CITY

PM2.5 emission load in the city is estimated to be 59 $\mathrm{t} / \mathrm{d}$. The top four contributors to PM2.5 emissions are road dust (38\%), vehicles (20\%), domestic fuel burning (12\%) and industrial point sources (11\%); these are based on annual emissions.

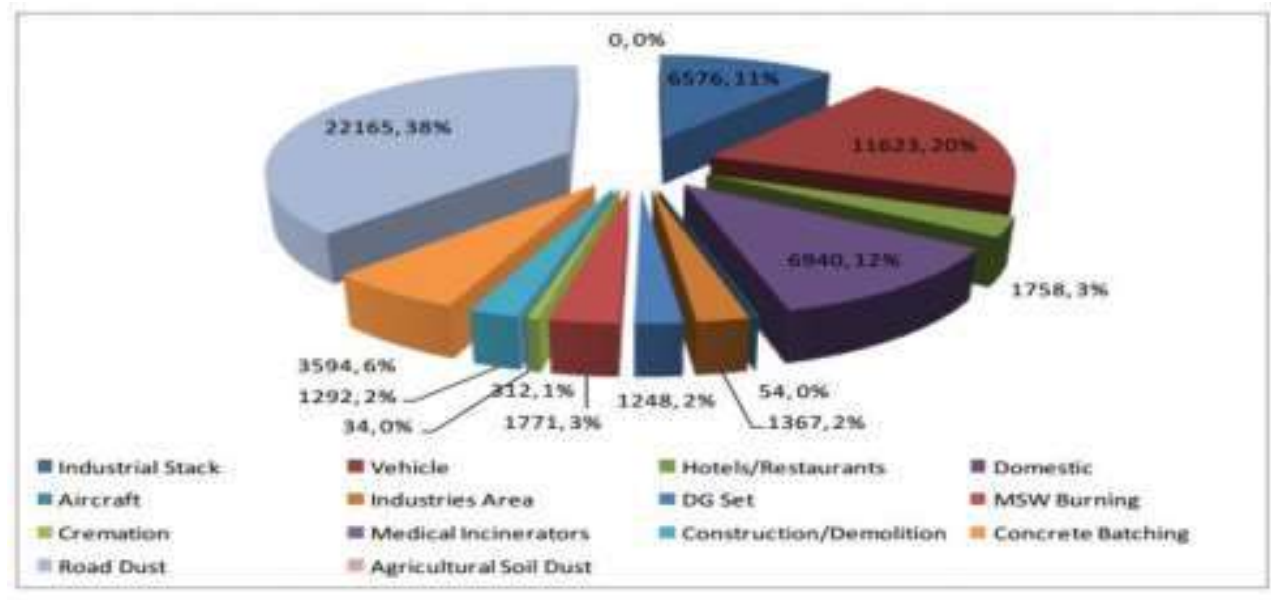

PM $_{2.5}$ Emission Load of Different Sources in the City Of Delhi

Image source: $\underline{\text { https://cdn.downtoearth.org.in/library/large/2016-11-04/0.54044700_1478264181_pm-2.jpg }}$ 
PM10 emission load in the city is estimated to be 143 $\mathrm{t} / \mathrm{d}$. The top four contributors to PM10 emissions are road dust $(56 \%)$, concrete batching $(10 \%)$, industrial point sources $(10 \%)$ and vehicles $(9 \%)$; these are based on annual emissions,"

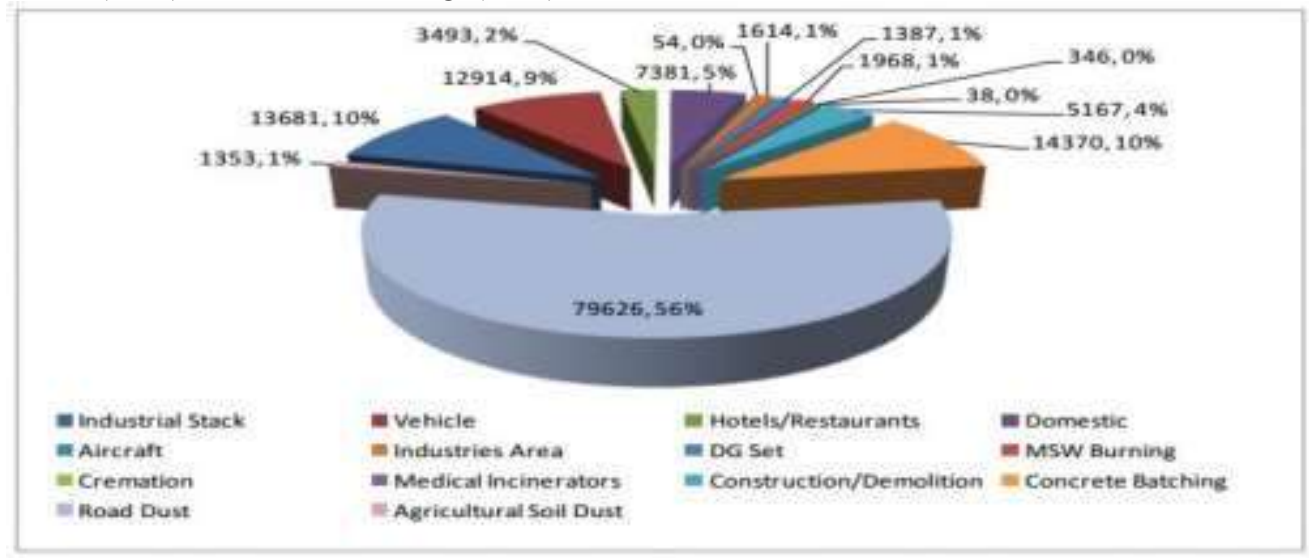

\section{PM $_{10}$ Emission Load of Different Sources in the City Of Delhi}

Image source: https://cdn.downtoearth.org.in/library/large/2016-11-04/0.32201500_1478264130_pm-10-in-delhi.jpg

The daily PM 10 and PM 2.5emissions from road dust in Delhi are estimated as 79,626 Kg's and $22,165 \mathrm{Kg}$ 's respectively. Delhi has got more than 8.9 million vehicles and diesel vehicles that emit about 7.5 times more particulates than petrol vehicles and produce more nitrogen oxide $\left(\mathrm{NO}_{2}\right)$. Exposure to even small doses of $\mathrm{NO}_{2}$ and $\mathrm{SO}_{2}$ cause adverse respiratory disorders like tracheal inflammation, Asthma, bronchoconstriction etc. In Delhi it is estimated every day about $98 \%$. of 142 tonnes of $\mathrm{S}_{2}$ and $60 \%$ of 312 tonnes of $\mathrm{NO}_{2}$ are being released into air.

\section{POLLUTION SOURCES IN DELHI}

To effectively address the pollution problem in Delhi, identifying major air pollution sources is essential. Delhi faces a severe air pollution problem due to the number of sources which are impacting the ambient air quality.

Major source of PM2.5 pollution is combustion based. For example, more than $95 \%$ of emissions from diesel, petrol, and natural gas combustion, open waste burning pollution, biomass burning pollution, and coal combustion at cook stoves and boilers, falls under PM2.5.

Major source of PM10 pollution is from mechanical processes - like dust, on the roads due to the constant vehicular movement, at the construction sites, and the seasonal dust storms. Close to $80 \%$ of the dust (that we commonly find on the roads) falls into the size fraction between PM2.5 and PM10.

\section{PROPOSED INTERVENTIONS FOR ATTAINING AIR QUALITY STANDARDS}

As a next step towards attaining air quality standards, since the NCR is a contiguous area with similarities in emitting sources, it is proposed that the control options should be strictly implemented for the entire NCR. With the implementation of control options in Delhi as well as NCR, the overall air quality in Delhi will improve significantly and expected PM10 levels will be $120 \mu \mathrm{g} / \mathrm{m} 3$ and PM2.5 will be $72 \mu \mathrm{g} / \mathrm{m} 3$.

\section{The proposed action plan for controlling $P M$ and $\mathrm{NO}_{\mathrm{x}}$ includes Hotels/Restaurants}

There are approximately 9000 Hotels/Restaurants in the city of Delhi, which use coal (mostly in tandoors). Flyash from this source is too high and contributes to air pollution. It is proposed that all restaurants of sitting capacity more than 10 should not use coal and shift to electric or gas-based appliances.

\section{Domestic Sector}

Although Delhi is kerosene free and $90 \%$ of the households use LPG for cooking, the remaining 10\% uses wood, crop residue, cow dung, and coal for cooking. The LPG should be made available to remaining $10 \%$ households to make the city $100 \%$ free from solid fuels.

\section{Coal and flyash}

Coal and fly ash contribute about 30 percent of PM10 and unless sources of flyash are controlled, air quality can be improved. However, two large power plants in city are also important sources of flyash. Flyash emission from hotels, restaurants and tandoors 
also cause large emissions and requires better housekeeping and proper flyash disposal.

\section{MSW burning}

Infrastructure for collection and disposal facilities of MSW has to improve and burning of MSW should be banned completely.

\section{Construction and Demolition}

The construction and demolition is a major source of PM10 emission and importantly it is a consistent source all through the year. The control measures for emission may include: wet suppression, wind speed reduction (for large construction site), proper disposed of waste, proper handling and storage of raw material and store the waste inside premises with proper cover. At the time of on-road movement of construction material, it should be fully covered.

\section{Ready Mix Concrete Batching}

The ready mix concrete used for construction activities releases large amount of flyash emission because pozzalan cement used in the process has about 35 percent flyash in it. The control measures include: wind breaker, bag filter at silos, enclosures, hoods, curtains, telescopic chutes, covering of transfer points and conveyer belts.

\section{Vehicular pollution}

The second largest source and most consistently contributing source to PM10 and PM2.5 in winters is Vehicular pollution. Various control options include the implementation of BS VI, introduction of electric and hybrid vehicles, traffic planning and restriction of movement of vehicles, retro-fitment in diesel exhaust, improvement in public transport etc have been proposed and their effectiveness has been assessed. In order to curb pollution, the citizens of are urged to support the odd-even vehicle rationing scheme.[4]

\section{Soil and road dust}

In summer, this source can contribute about $26 \%$ to PM10 and PM2.5. The silt load on some of the Delhi's road is very high and silt can become airborne with the movement of vehicles and the estimated PM10 emission from road dust is over 65 tons per day. The potential control options can be sweeping and watering of roads, better construction and maintenance, growing plants, grass etc. to prevent re-suspension of dust.

\section{Industries and Diesel Generator Sets}

Industries: Several measures have been taken to control emissions in the industry (including relocation), especially in small and medium size industries. However, it is recommended industries use light diesel oil (LDO) and high speed diesel (HSD) of sulphur content of $500 \mathrm{ppm}$ or less in boilers or furnaces, if not already being used; expected PM control will be about 15 to $30 \%$ from this source and SO2 emissions will become negligible.

Diesel Generator Sets: The primary pollutants from internal combustion engines are oxides of nitrogen and PM. For Delhi and NCR, the sulphur content should be reduced to $500 \mathrm{ppm}$ in HSD (if not already in use) as has been done for vehicles; a reduction of 15 to $30 \%$ of PM emission from this source is expected. It will have a major impact on reduction of SO2 and secondary particles. The DG sets should be properly maintained and regular inspection should be done. All efforts should be made to minimize uses of DG sets and regular power supply should be strengthened.

\section{Secondary particles:}

These particles are expected to source from precursor gases (SO2, and NOx) which are chemically transformed into particles in the atmosphere. Mostly the precursor gases are emitted from far distances from large sources. For sulfates, the major contribution can be attributed to large power plants and refineries and contribution of NOx from local sources, especially vehicles and power plants can also contribute to nitrates. Behera and Sharma (2010) for Kanpur have concluded that secondary inorganic aerosol accounted for significant mass of PM 2.5 (about 34\%) and any particulate control strategy should also include control of primary precursor gases.[5]

\section{Secondary Organic Aerosols}

It is estimated that the SOA is about 17 percent of total PM2.5 in Kanpur, another city in Ganga basin. This implies that emissions of VOCs (volatile organic compounds) need to be controlled both in and outside of Delhi, as SOA can be formed from VOC sources at far distance from the receptor. It is recommended that all petrol pumps in Delhi should install vapour recovery system to reduce VOC emissions both at the time of dispensing petrol/diesel but also at the time of filling of storage tank at the petrol pumps.

\section{Biomass burning}

The enhanced concentration in OctoberNovember is possibly due to the effect of postmonsoon crop residue burning (CRB). The CRB should be minimized if not completely stopped. All biomass burning in Delhi should be stopped and strictly implemented. Managing crop residue burning in Haryana, Punjab and other local biomass burning is important. Potential alternatives to CRB: energy production, Biogas generation, commercial feedstock for cattle, composting, conversion in biochar, raw material for industry.

\section{CONCLUSION}

Since the enactment of the Air Act 1981, air pollution control programs have focused on point and area source emissions. Nonetheless, many cities in the country still face continuing particulate pollution problems despite the high level of control applied to many point sources. To address the air pollution problem in the city of Delhi, identifying emission sources (industry, traffic, power plants, local power 
generation, small scale industries etc.), Chemical speciation of particulate matter (PM) and measurement of other air pollutants needs to be studied. Selection of best control options from the developed control scenarios and implementation of control options in a time-bound manner is highly recommended. In addition to the above control options, some local efforts will be required to ensure that city of Delhi and NCR attain the air quality standards all through the year and possibly for many years to come.

\section{REFERENCES}

1. Delhi pollution: Why govt needs to look beyond ad hoc measures to make city safe for breathing available at https: / / www.indiatoday.in/india/story/delhi-

pollution-smog-arvind-kejriwal-odd-even-1083138-

2017-11-09

2. Delhi faces its worst smog; CSE calls for emergency action available

https: / / www.downtoearth.org.in/news / air/delhi-faces-

its-worst-smog-in-17-years-cse-calls-for-emergency-

action-56218

3. Comprehensive Study on Air Pollution and Green House Gases (GHGs) in Delhi available at http: / / environment.delhigovt.nic.in/wps/wcm/ connect /735190804acf830c8eec8f09c683c810/ Final+Report 09Jan2016.pdf?MOD =AJPERES\&lmod $=1109294014$ $\&$ CACHEID $=735190804 a c f 830 c 8 e e c 8 f 09 c 683 c 810$

4. Delhi Air Pollution LIVE Updates: SC Lists Out Penalties for Violation, Asks Delhi for Previous Odd-Even Report available

https: / / www.news18.com/news/india/delhi-pollutionlive-updates-odd-even-scheme-today-smog-air-qualityharyana-punjab-stubble-burning-2372507.html

5. Behera, S. N. and Sharma, M., (2010) Reconstructing Primary and Secondary Components of PM2.5 Composition for an Urban Atmosphere. Aerosol Science and Technology, 44 (11), 983-992 